\title{
THE OPINIONS ON FORCE PROTECTION IN ASYMMETRIC OPERATIONS
}

\author{
Ionel COTOARBĂ \\ “Carol I" National Defense University, Bucharest, Romania \\ ionelcotoarba@yahoo.com \\ Ion MITULETU \\ “Carol I" National Defense University, Bucharest, Romania \\ mituletuion@yahoo.com
}

\begin{abstract}
The future conflicts will take place in increasingly complex operational environments and will largely include conventional, asymmetric or hybrid opponents. The battle space that has acquired new valences and the asymmetrical nature of the current operational environment require the perpetual reconfiguration of the rules of engagement. Within the asymmetric actions, the enemy will focus their efforts on attacking vulnerable military structures, which have a degree of protection inadequate for the operational situation. Therefore, the protection of force is a key element in the effective management of situations, maintaining the pace of actions and the ability to fight in the development of asymmetric operations. From the range of asymmetric actions that manifests itself globally, we aim to conduct an analysis focused on force protection measures specific to counterinsurgency, counter-guerrilla and counter-terrorism operations. The place and role of force protection in asymmetric operations attest to the fact that specific measures are aimed in particular at maintaining the morale and combat capability of their own forces throughout the range of missions performed, as well as protecting the civilian population in the area of action.
\end{abstract}

KEYWORDS: asymmetric operations, asymmetric threats, force protection, risks, vulnerabilities

\section{Introduction}

The recent history has shown that military operations have a multinational focus, and conventional actions intertwine with asymmetric ones.

In the last decades, military missions have diversified and amplified, becoming more and more complex, entering a new horizon of requirements and exigencies, imposed by the new extended range of asymmetric dangers and threats, including by far, the terrorist ones which stand out.
The sphere of dangers, threats and vulnerabilities has greatly expanded, from chemical, biological, radiological and nuclear (CBRN), to those specific to cyberspace, hybrid or asymmetric, and the risks imposed or assumed have increased proportionally.

We can note, at the beginning of this millennium, that most conflicts, especially the armed ones, continue to have the three major characteristics of any military or civil-military confrontations such as symmetry (proportionality), dissymmetry 
(non-symmetry, disproportionality) and asymmetry (dynamic proportionality), but as weapons have been perfected and society's vulnerabilities have increased, conflict has shifted significantly to dissymmetry and asymmetry (Dinu, 2010, p. 49).

Instabilities and unpredictability around the world can reactivate frozen conflicts, which would increase cases of asymmetric and hybrid conflicts, according to regional interests (White Paper on Defense (WPD), 2021, p. 11).

Today, perhaps more than ever, military specialists are trying to reach a consensus on the typology of war. American and British experts say that the future type of war is an asymmetric, counterinsurgency war, a war that requires more stability, support and reconstruction operations, effects-based actions, other than traditional military actions.

More and more military analysts believe that unconventional actions used in response to conventional forces have been classified as asymmetric.

When we call attention to an asymmetric threat, we refer to that type of threat that emanates the potential use of different methods, techniques, procedures and means, sometimes categorized as atypical to combat or avoid the opponent's strengths, while exploiting their vulnerabilities and weaknesses, in order to obtain disproportionate results (The Doctrine of the Land Forces Operations in the Romanian Army (DLF), 2017, p. 39).

Asymmetric operations cover a wide range of actions of military and paramilitary forces, which have a lengthy manifestation and are carried out with the support of or by the indigenous population (Herciu, 2016a, p. 72).

However, conventional armed forces in the service of nations will remain the main deterrent, as it happened in the conflict in Ukraine, where the Russian Federation concentrated divisions on the border, only to create a diversion and show its strength.

\section{Research Methodology}

Considering the aspects presented in the introduction, further on using the scientific methodology based on the study of specialized sources and empirical research relied on observation, the study will focus on the typology of asymmetric military conflicts and particularities of force protection in asymmetric military operations.

Purpose: We aim to conduct an analysis focused on force protection measures in counterinsurgency, counterguerrilla and counter-terrorism operations, in order to identify the most apropriate ways of action, and also, the effective force protection measures at all tactical, operational and strategic levels.

In addition, the conclusions substantiation was also based on our experience gathered in: operations Afghanistan TO (as HQ officer), numerous national and multinational military exercises, and CREVAL evaluation and assessment (as team member) of military structures.

\section{Typology of Asymmetric Military} Conflicts

By joining NATO and the EU, Romania has assumed both the benefits and the risks arising from this membership, even if no major threats to national security are currently identified, unconventional and asymmetric risks constantly requiring effective monitoring and countermeasures, in close cooperation with European and Euro-Atlantic partners.

The events of the last decades in the world can contradict the reported ones, referring to the evolution of the situation in Ukraine, to the actions carried out by the Islamic State, as well as to the situation in Syria which, although not close to Romania's borders, indirectly influences national security by merging and transiting waves of refugees near or even within our borders.

Undoubtedly, the emergence of new threats such as terrorism, unresolved conflicts, authoritarian regimes, uncontrolled 
migration and the structure of new conflicts such as ethnic disputes, guerrilla warfare, counterinsurgency or counterterrorism have led to changes in the projection of military power, forces and mode of action in the operational environment.

In addition, changes in other areas, such as political, social, economic and also technological, have a significant impact on the security environment.

It is very clear that the asymmetry will exist in the future and certainly the weak one, even if we are talking about states, terrorist organizations, insurgents, guerrilla groups, etc. does not want a direct confrontation and will resort to new asymmetric methods of harassment, claimed or unclaimed violent attacks, from seemingly randomly chosen terrorist attacks to the detonation of improvised explosive devices, even with a chemical or radiological charge (Isnard, 2001).

Even the great Chinese strategist Sun Tzi stated in his work that it is not enough to be strong or to dominate numerically, if you do not have skill and intelligence, victory cannot be guaranteed.

Specifically, "the whole art of war is based on deception. Therefore, if you are capable, simulate incapacity; if you are active, simulate passivity. If you are close, make them think you are far away and if you are far away, make them think you are close. Lure the enemy to trap him; simulate disorder and strike him; avoid him when he is strong. Make him feel you are inferior and encourage him to confront you. Don't leave him alone for a moment, harass him. Attack him when and where he is not prepared; act when he does not expect such a thing" (Sun, 1976, pp. 24, 33).

In other words, study your opponent very well, identify the window of opportunity and exploit his vulnerabilities, know his strengths and avoid being surprised. Today, perhaps more than ever, the world's great military powers tend to replace human intelligence with artificial intelligence, with increasingly sophisticated means and technologies capable of making the decision on man's behalf, and once the "red button" is pressed, only time should be the invariable from the equation of finding out the effects.

Simplifying the above, a weaker army seeks to gain an advantage over a stronger one, and a superior army seeks to win the war quickly, with minimal losses, even to zero, hence the phrase "they won the victory without being fired a cartridge".

In the future, we estimate that opponents will seek new ways of responding asymmetrically, through cyber attacks, the use of chemically and even biologically loaded weapons, and guerrilla warfare and terrorism will be more real, with psychological impact on forces that can induce decisional blockages and syncopes in ensuring freedom of movement and taking over or maintaining control, at least over one area.

Until the 9/11 terrorist attacks on the United States, they were not really taken into account, but rather treated as lowintensity actions, with no effects of strategic importance. Subsequently, many countries have joined forces in a broad action to eradicate these terrors, through targeted attacks on old and new terrorist and guerrillas organizations or insurgents.

We estimate that this struggle, the war of the century, will be a lenghty one, perhaps even an war of attrition for the forces involved, in the context of the large number of immigrants from countries under terror such as Afghanistan and Syria.

It is understandable that the goals of the parties in the conflict are different and spring from the methods of promoting their policy, but overall it is not necessarily a military confrontation, but rather a cultural, economic, religious or informational one (Liddell, 1973, p. 368).

The power, demographic, cultural and technological gaps have induced, among some specialists, the fact that the victory of 
the strongest, greatest, the one who owns high-tech means will be easy, but recent history has shown the opposite, being instructive the wars in Gulf or Yugoslavia, which successfully fall into the typology of asymmetric conflicts.

A fundamental feature of current asymmetric conflicts is the fluidity of space, the depth that derives from the enemy's ability to engage in all levels of military art and in at least two environments of confrontation, in order to rapidly weaken their combat power and make them surrender (Paul, 2000, p. 102).

In other words, the asymmetric conflict concerns the atypical response of non-state actors to the actions of state actors, in order to achieve the proposed objectives in the event of a technological, conventional and decisional gap between the belligerent parties (Mitulețu, 2018, p. 50).

The non-contact war did not arise against the background of the revolution at the level of military art, but rather under the pressure of civil society, especially after the terrorist attacks on the twin towers in the US as a result of which, in addition to material and financial losses, a significant number of human lives were lost.

Certainly any commander or leader wants to achieve victory with losses tending to zero, or at least, a military superpower with state-of-the-art technology and equipment has the perception that this goal can be achieved, while accepting certain costs, but of a material and financial nature.

Some military analysts believe that such an asymmetric conflict could exist, but as a temporarily limited stage, within the strategic surprise and which ends with the inevitable, the contact between the two military groups.

The strategic objective of non-contact warfare is to subdue the adversary, ahead of time, without giving him a chance to fight, by aggressive and synchronized engagement in all means of confrontation, by all available means, from political, diplomatic and informational, to the terrestrial, aerospace and cosmic ones.

The modern version of such a conflict is the success of the US military against Iraq led by Saddam Hussein, the wellknown Gulf War.

There is the perception of some that this would be possible only in one sense, from the strong, high-tech one to the weakest, lacking high-performance combat equipment, but history has shown, and certainly will show us, that also in the category of asymmetrical reactions are also the attack of the isolated on the coalition, of the disappointed on the imposing one, relevant through a wide range of procedures and forms of manifestation of asymmetric warfare, such as total war, guerrilla warfare, terrorism or insurgency.

Total or popular warfare is perhaps the most representative form of manifestation of asymmetric warfare, which comes as a mass reaction of the entire people, to a strong attacker, especially in terms of super equipments and exceptional military capabilities.

This type of conflict, representative of the age of nations, tends to disappear in the context of dizzying technological development and the focus on the development of modern, professional armies, strengthened by the wars in Iraq (1991) or Yugoslavia (1999), when nations were practically unable to have a conclusive reaction. In other words, total war is losing ground to non-contact war or should not even be treated as a modern approach to a multidimensional attack in a computerized society.

The guerrilla war does not lose its global manifestation, it remains a thorn even in the face of military forces, an asymmetric threat difficult to combat and due to the seemingly disorderly mode of operation, which is out of the ordinary. Guerrilla fighters act in small groups, by surprise, violently, according to the rules of armed actions, by terrorist means, on vulnerabilities or strengths, day or night, 
generally for dethroning governments and seizing power, obtaining financial or territorial advantages.

At the international level, considerable efforts are being made, coalitions and alliances are being formed, common databases for stopping the growing actions of recognized groups such as the Colombian, Afghan or Chechen guerrillas.

We specify that guerrilla actions should not be confused with terrorist actions, even if they use methods and procedures specific to terrorism. The guerrilla has limited goals, operates in a defined space, even if it acts against an army, it will not engage in conventional operations, face to face.

The terrorism is perhaps the most pronounced and aggressive form of asymmetric manifestation of the new beginning of the millennium towards the security of states, in particular, and world peace in general. There is almost no state in the world that does not question the protection against this scourge that vehemently opposes international humanitarian law and democracy (Yacoub, 2000, p. 33).

Perhaps the reaction of the United States to declare an unprecedented campaign of total war came as something long-awaited, normal, as the initiative of an older brother, strong, prepared, equipped and able to take the reins of the problem and start an expensive action, of magnitude, but also of attrition. Of course, many states have formed a coalition and are ready to act at any time through the specific capabilities of combating organized crime, the underworld, drug traffickers, information and military terrorism supported by certain states.

Certainly, terrorism remains an asymmetric threat, evident in the conditions of illegal possession of stocks of chemical fighting agents, radioactive material and means of strike, even rudimentary. The terrorists had, discover, develop and carry out new methods, operating improvisations that would create terror, discomfort and as many human and material losses as possible.
The insurgency operates with diversified tactical capabilities, acting, in principle, to achieve strategic level effects. Usually, they do not engage in direct confrontations such as conventional forces, but resort to asymmetric tactics to obtain advantages, such as dispersion among the local population. These unconventional forces are not necessarily physically or conceptually bound by national borders or legitimate conventions (DLF, 2017, p. 33).

The insurgent groups are categorized as armed groups of some rebel movements, with claims of an ethnic, social or religious nature seeking, by any means to produce political change in a certain geographical or administrative area, benefiting from the population support. As a form of struggle, the insurgency is initially local or regional in nature and increases in intensity, encompassing a growing area of territory and a significant number of partisans among the population, until the conditions necessary for political change are reached (Herciu, 2016b, pp. 41-42).

\section{The Features regarding the} Protection of Force in Asymmetric Military Operations

It should be noted that the current armed forces must be reconfigured, equipped and trained differently from the present, in order to respond effectively to global asymmetric threats, to which the army cannot remain impassive, but has the obligation, at least morally, to protect its citizens and to make a common front with the allies, in the face of insurgent actions, terrorist attacks, guerrilla warfare, organized and commanded crime, hostagetaking, separatist and nationalist actions, anti-drug campaigns, etc.

We estimate that in the near future there will be no more military confrontations on broad fronts, but rather surgical actions, often violent, by employing adaptable and flexible modular structures, such as special operations forces 
or combat groups with the involvement of specialists in the fields of interest, in order to face indoctrinated fighters, with an extreme physical and mental training, who are willing, as to order or in a certain borderline situation, to sacrifice themselves without hesitation.

The tendency is for such asymmetric actions to remain under the protection of anonymity and to be complemented by cyber attacks on critical infrastructure points, government organizations, strategic defense systems to amplify the effect of inducing terror and exiting the cannons.

It is the lack of the imprint of the increasingly violent attacks, of the reduced evidence discovered in the area of the event, of the unclaimed by a recognized group, that leads us to a deep inclination on the issue to identify effective ways of action, but also effective measures of force protection at all tactical, operational and strategic levels.

At the strategic level, safeguard measures must first be taken to avoid surprise, by strengthening inter-agency collaboration with coalition partners to ensure a viable exchange of information in order to timely identify imminent threats and risks of an attack. Coalitions do not make us stronger, but they certainly make us less vulnerable and bring more stability and protection against aggressive asymmetric threats. Our country's accession to NATO and the EU, as well as strategic partnerships, especially with the United States, are important steps in achieving a horizon of strategic security, regional and local stability.

Now, with a simple request, in a very short time, any EU member state can undertake a monitoring action in an area of interest, from issues related to border security, support for the execution of missions, issues related to migration, to port or land transport activities, explained Sorin Ducaru in his capacity as director of EU SATCEN (The Romanian who deals with the Satellites of Europe, 2021).
It is clear that the number of partnerships, coalitions and alliances is directly proportional to the protection factor, even of the armed forces.

On the other hand, it is necessary to develop a strategy for retaining and attracting talent and specialists in various fields of interest (The National Security Strategy, 2020, p. 35), complemented by ensuring the legal framework for the creation and development of new military capabilities, tailored to the requirements of the operational environment.

Consistent with our present and current possibilities, it is difficult to dominate or conquer the space of asymmetric confrontations, but a permanent and realistic assessment of the threats, risks and vulnerabilities through which to have appropriate reactions is an intrinsic requirement and obligation.

In this context, we appreciate the fact that, at a strategic level, force protection implies the existence of a credible and efficient information system that allows the knowledge and permanent monitoring of the situation in the theater of operations to ensure the prevention of surprise and increase the fighting power of its forces in the spectrum of asymmetric operations.

At the operational level, perhaps the most intelligent force protection movement, in response to asymmetric threats, is the presentation and media coverage of military structures, as well as military defense capabilities, within the large-scale exercises conducted in an allied, multinational, interinstitutional, joint context or interarms, which present new concepts of discouragement, but also the possibilities of engagement in case of potential asymmetric actions or of other nature.

For example, the opening of the NOBLE JUMP 2021 Multinational Exercise, which took place in Romania between May 19 and June 2, 2021, by raising a drone, leads us to the message that NATO is a credible alliance and adaptable 
to changes in the operational environment. At the same time, NATO forces practiced the deployment in a very short time in Romania of some contingents from other European countries (The multinational exercise NOBLE JUMP, 2021).

These show-forces military exercises aim to train its own personnel and align with the operating procedures of the allies, develop relations with partners and achieve a common operational language, as well as our recognition as a non-expansionist nation, conservative of cultural values and promotion of a climate of stability and trust at regional and global level.

The military presence of the American armed forces on the territory of Romania reiterates the indisputable proof of solidarity and involvement in achieving common interests and objectives.

In this sense, at operational level, force protection has a joint, integrated and multinational character, thus becoming the multidimensional force protection, which ensures all specific measures to maintain and enhance the combat capability of its own forces in a hostile operational environment.

At the tactical level, the fluidity of the operational environment and the increasing number of terrorist acts call for a reconsideration of missions, principles and procedures for action and an increasingly active involvement of military capabilities in the face of unprecedented asymmetric threats and violence, such as the January 7, 2015 attacks, directed against Charlie Hebdo magazine or the declaration by the WHO in March 2020 concerning COVID 19 pandemic as a result of the sudden spread of the disease caused by the SARS-CoV-2 virus.

In this context, in which the politics has decided to engage military forces in the event of unforeseen situations, there is a need, more than ever, for an adaptation and rise of flexible, modular, specialized military structures, equipped with high-tech technique and equipment, performing a wide range of missions and responding to a variety of asymmetric threats.
It is possible to create such modular military structures, which can be dimensioned according to the magnitude of the event, the duration and the type of engagement area, through a correct analysis and evaluation of existing structures. This assessment must take into account recent events, diversification of terrorist attacks and modes of operation, use of chemical agents in combination with improvised explosive devices, lack of control regarding the spread of viruses, but also lessons learned from the occurrence of these events, as well as the achievement of a necessary legislative framework.

For the multidimensional accomplishment of the protection of the force and of the population in the area of operations, specialized structures are needed, at least in the fields and operating environments of the opponents.

In this regard, we appreciate the fact that, at a tactical level, structures, tactics, techniques and procedures specific to force protection are integrated for the whole range of asymmetric operations, combined with measures to protect the civilian population in the area of action.

Having as references the specificity of the current operational environment, the general force protection measures, the typology of asymmetric operations and the essential characteristics, we aim to perform an analysis focused on force protection measures specific to counterinsurgency, counterguerrilla and counterterrorism operations.

In counterinsurgency operations, the center of gravity is shaped around the local population, which has a decisive role in carrying out all types of actions in the area of operations. The actions of the HUMINT, CIMIC and PSYOPS structures carried out by the coalition forces are essential elements in forming a positive opinion and encourage the locals to provide permanent information on the dynamics, diversity and scale of the insurgent actions, so necessary for the correct assessment of 
the operational environment, and adequate protection of their own forces, both in the layout area and during the performance of specific actions, such as patrols, search, and hiring actions of local leaders, identification and blocking of transit routes or monitoring and neutralization of arms depots, ammunition, equipment and other devices specific to carrying out the harassment fight by the joint multinational force.

Given the rather long duration of such a conflict, we believe that the force involved in counterinsurgency actions must be carefully dimensioned, depending on the risks, threats, vulnerabilities, the value of the enemy, the type of mission and the capabilities available.

Thus, we are also talking about structures with a role in ensuring the protection of the force that are not part of the task force, but can act in accordance with the evolution of the situation, being able to intervene, on order, in a relatively short time to settle a situation.

The analysis of recent conflicts shows that in counterinsurgency operations the emphasis must be on the physical protection of the layout area, disguise, electronic protection, and influencing local population through CIMIC actions, psychological protection, media protection against fake news, EOD protection of DEI even with chemical or radiological load, medical insurance, air protection, as well as the protection of the local population that supports their own actions.

Forces intended to carry out counterterrorist actions must be able to cover a wide range of actions in front of a complex, innovative opponent, permanently adaptable to the requirements of the operational environment.

When we talk about terrorism, we have in front of us an opponent with high financial potential, coming from various illicit actions or even from some state actors.
Thus, we identify well-organized terrorist groups, equipped with high-tech equipment and means of combat, even with specialists recruited from various fields and who are able to launch cyber attacks, to make improvised explosive devices, even chemical charge, to bring contribution to the training of other followers, ready at any time to trigger terror and a significant number of victims and material damage, with a globally significant impact.

We mention here the attacks on the twin towers at the World Trade Center on September 11, 2001, the attack on Charlie Hebdo magazine in Paris on January 7, 2015 , or the sarin gas attack on a Tokyo subway station on March 20, 1995.

Targeted attacks on computer networks may seem harmless at first glance, but by taking control of critical technological processes can cause property damage and a significant number of casualties. This phenomenon is called cyber terrorism, a component part of the terrorist phenomenon (Herciu, 2016b, p. 33).

The diversity of such bloody attacks forces us to be vigilant and to develop credible structures, adequate to counter such threats. It is encouraging to know that in the conditions of having stocks of chemical fight agents and radioactive material, many states have developed CBRN defense structures, capable of intervening in resolving unwanted events, along with EOD elements.

From the history of terrorist attacks in recent decades, we believe that the most appropriate measures to protect the general population and the force, in particular, are those related to the specific action of intelligence services, including the exchange of information at interagency or interstate level; developing and training special operations force groups to intervene promptly and effectively in the event of armed attacks; CBRN and EOD defense structures that are able to act in contaminated conditions/environments or 
with improvised explosive devices; cyber defense cells capable of an effective response to the multiplication of attacks in cyberspace; PSYOPS elements to combat the propaganda messages of terrorist organizations and to convey messages of calm and return to normalcy.

Starting from the limited characteristics and objectives of guerrilla groups, we appreciate that counter-guerrilla operations take place in a defined space, thus we can discuss a military force sized according to the value of the opponent, the extent of risks and threats, and trained to act under any conditions of time and season, with specific combat in the urban environment.

As a solution to the violent harassment attacks of guerrilla groups, which usually avoid direct confrontations, a diversified package of structures is outlined to combat these asymmetric threats and provide an appropriate protection factor, a multiplier of combat power and a determinant of freedom of movement in such a complex environment. Intelligence structures, research by all means, including drones, make a significant contribution to the provision and protection of the information so necessary in support of the decision of the mission commander. The characteristic of the guerrilla to act, apparently out of the ordinary, forces the intelligence services to a deep inclination on the issue, especially to avoid surprise.

Also, EOD protection measures, air defense, CBRN defense, ballistic protection, including human protection are minimal measures in the face of such villainous actions.

Specialized forces integrated in elite groups, such as assault detachments, teams and commando groups or forces for special operations, trained to carry out actions in force, with great destructive power, have an indisputable role in achieving success (Herciu, 2016a, p. 70).

At the same time, inter-institutional collaboration, synergistic action of all structures in a state's security system, including forces for special operations can lead to the reduction and even elimination of such guerrilla groups that continue to bring terror to various places on the planet.

In conclusion, we believe that future conflicts will be predominantly asymmetric, cybernetic and hybrid, and in order to have adequate protection of the force we must form a new culture of addressing risks and threats through proactive actions, and not reactive, in the face of an enemy increasingly difficult to outline, volatile or invisible.

\section{Conclusions}

In the face of asymmetric challenges, conventional forces will have to carry out a wide range of tactical actions and operations in support of politico-military objectives and, perhaps more than ever, be aware of the need for cooperation with other national or international non-military bodies as a necessary and efficient approach to complex threats induced in the current operational environment

The success of the fulfillment of objectives is conditioned by the understanding of the doctrines and principles of planning, preparation and execution of force protection missions in asymmetric operations.

All commanders must anticipate the use of innovative methods, techniques, tactics and procedures by the adversary and rapidly develop force protection actions, based on deception, advanced technologies and experience, while continuously exploiting the effects of actions planned by their own forces.

In the end, we appreciate the fact that the existence of an increasingly dynamic and volatile operational environment, marked by the reconfiguration of atypical and unconventional risks, threats and vulnerabilities, requires the Romanian army to act to develop and improve force protection structures and procedures to 
ensure the permanent supervision of the situation, the prevention of the surprise, the maintenance of the morale and the combative capacity of the forces, as well as the protection of the civilian population within the asymmetric operations, such as insurgency, guerrilla or terrorism.

\section{REFERENCES}

Dinu, M.S. (2010). The role of cultural factors in military actions. Bucharest: "Carol I" National Defense University Publishing House.

Herciu, A. (2016a). The evaluation of the hybrid operational environment from the perspective of lessons learned. Bucharest: "Carol I" National Defense University Publishing House.

Herciu, A. (2016b). The leadership and use of combined forces in hybrid conflicts. Bucharest: "Carol I" National Defense University Publishing House.

Isnard, J. (2001). La guerre "asymétrique" entre les terroristes et les Etats-Unis. Le monde, $12 \mathrm{~h} 24$.

Liddell, H. (1973). Strategy. Indirect actions. Bucharest: Military Publishing House.

Ministry of National Defense. (2021). White Paper on Defense (WPD). Bucharest.

Mituleț, I. (2018). Changing paradigms in conflict approach. Journal of the National Security Academy of Sciences, No. 1.

Paul, V. (2000). The war of the third millennium. Bucharest: D.B.H. Publishing House.

Romania Presidential Administration. (2020). The National Security Strategy of Romania for the period 2020-2024. Romania, Bucharest.

Sun, T. (1976). The art of war. Bucharest: Military Publishing House.

The doctrine of the land forces operations in the Romanian Army (DLF). (2017). Bucharest.

The multinational exercise NOBLE JUMP. (2021). Available on: https://www.hotnews. ro/stiri-defense-24811393-exercitiu-militar-nato-romania-nomblejump-21-reactie-rapida-ajutor-atac-aliat.htm, accessed at 07 June 2021.

The Romanian who deals with the Satellites of Europe. (2020). Available on: https://www.digi24.ro/stiri/externe/ue/romanul-care-se-ocupa-de-satelitii-europei-am-urmaritincendiul-de-la-cernobil-ar-fi-putut-avea-efecte-complicate-1301813, accessed at 07 June 2021.

Yacoub, J. (2000). Minorités nationales et prolifération etatique. La revue internationale et stratégique, No. 37. 